\title{
Current Status of Management for Poor-grade Patients with Ruptured Intracranial Aneurysm
}

\author{
Kyu Chang LeE, M.D.
}

Summary: To establish a management strategies for poor-grade patients after aneurysmal subarachnoid hemorrhage (SAH), medical records were analyzed for 166 patients who were in Hunt and Hess Grade IV or V among 588 consecutive cases with ruptured intracranial aneurysm admitted during the past 5 years. Causes of unfavorable outcome (poor or dead) in those 166 patients were evaluated to improve the management outcome.

Overall management results of the 166 poor-grade patients were favorable (good or fair) in 71 (42.8\%), unfavorable in 95 ( 78 dead, 17 poor). Direct clipping was performed in 90 patients, and the results were favorable in $69(76.7 \%)$ and unfavorable in 21(23.3\%). Surgery was not done in 76 patients because 41 were moribund on arrival, 15 deterioration due to rebleeding, 7 severe brain swelling, 5 serious medical illness, one severe delayed ischemic deficits (DID), and one cerebral infarction following angiography, and 6 refused surgery. Seven patients survived in non-surgery group (2 fair, 5 poor). Direct effects of aneurysm rupture (34.8\%) and early rebleeding (34.8\%) were the major causes of unfavorable outcome in Grade IV patients, while it was direct effect of aneurysm rupture (91.8\%) in Grade V patients.

As rebleeding is the only preventable cause of unfavorable outcome, urgent management is necessary to prevent rebleeding, especially for grade IV patients. Grade IV patients should be treated aggressively with direct clipping for non-complex aneurysms or for patients with hematoma, and coil embolization for patients with poor surgical indication.

\section{Introduction}

Aggressive management in poor-grade (Hunt \& Hess Grade IV or V) patients remains controversial. ${ }^{2) 3(4) 10) 12) 14)}$ 15)18)19) Poor-grade patients have been subjected to conservative management first mainly due to low probability of favorable outcome. The possibility of aggressive surgical management has been determined only after improvement of clinical grade. ${ }^{16) 18)}$ Difficulty in surgery, high mortality and morbidity, and low functional recovery make neurosurgeons reluctant to perform early direct surgery in poor-grade patients. ${ }^{6) 18)}$ Recent reports of favorable results from early surgical management of the good-grade patients encourage neurosurgeons to manage the poor-grade patients in an active manner. ${ }^{3) 912) 14)}$ Despite of several

\author{
Key words: \\ - subarachnoid hemor- \\ rhage \\ - ruptured intracranial \\ aneurysm \\ - poor-grade patients \\ - rebleeding
}

Surg Cereb Stroke

(Jpn) 26: 5-9, 1998

Department of Neurosurgery, Yonsei University College of Medicine (Received July 23, 1997) [Mailing address: Kyu Chang LEE, M.D., Department of Neurosurgery, Yonsei University College of Medicine, C. P. O. Box 8044, Seoul, 120-752 Republic of Korea] 
tomography (CT) and the presence of an aneurysm on fourvessel cerebral angiography. One hundred and sixty-six patients, presented in poor-grade on admission, were subjected to retrospective analysis.

\section{Management}

Emergency surgery was performed for deteriorating patients with an intracerebral hematoma. The remaining patients were managed at the Neurosurgical Intensive Care Unit until improvement of neurological state. We used ventriculostomy for an acute hydrocephalus, mannitol for increased intracranial pressure, and nitroglycerin for hypertension. We performed surgical clipping of the ruptured aneurysm as soon as possible in patients who showed clinical improvement. Other categories of poorgrade patients requiring early surgery included acute hydrocephalus, and poorly controlled hypertension with agitation. Early clearance of subarachnoid clot on followup CT indicates slack brain at the time of early surgery and better outcome. Surgery was delayed in patients with a complex aneurysm where undue brain retraction and prolonged temporary arterial occlusion are anticipated. Ninety of the 166 poor-grade patients (54.2\%) underwent surgical clipping of the ruptured aneurysm (within 72 hours in 29 patients, over 72 hours after the last rupture in 61 patients). Surgery was delayed in 25 patients due to a late presentation to our institution. After surgical clipping of the ruptured aneurysm, moderate hypertension was induced with dopamine or dobutamine, and the hematocrit was maintained at 25-33\% for prevention or treatment of delayed ischemic deficits (DID). Intravenous use of a calcium antagonist, nimodipine was started routine base from the time of admission. Papaverine was infused into the

Table 1 Clinical grade and management outcome

\begin{tabular}{lccc}
\hline Grade & \multicolumn{2}{c}{ Outcome $(\%$ in row) } & Total \\
\hline Good $^{*}$ & $385(91.2)$ & $37(8.8)$ & 422 \\
Poor $^{*}$ & $71(42.8)$ & $95(57.2)$ & 166 \\
\hline Total & $456(77.6)$ & $132(22.4)$ & 588 \\
\hline
\end{tabular}

* Hunt and Hess Grade I, II, or III, ** Hunt and Hess Grade IV or V

Table 2 Management outcome of poor-grade patients

\begin{tabular}{llcc}
\hline $\begin{array}{c}\text { Hunt and } \\
\text { Hess grade }\end{array}$ & \multicolumn{2}{c}{ Outcome (\% in row) } & Total \\
\hline IV & $61(57.0)$ & $46(43.0)$ & 107 \\
V & $10(17.0)$ & $49(83.0)$ & 59 \\
\hline Total & $71(42.8)$ & $95(57.2)$ & 166 \\
\hline
\end{tabular}

selected cerebral arteries when the patients develop postoperative vasospasm.

\section{Data analysis}

We analyzed data from medical records and imaging studies in regard to amount of hemorrhage, location of aneurysm, incidence of rebleeding and DID, and factors related to unfavorable outcome, and compared them between good and poor-grade patients. The results of treatment, causes of unfavorable outcome, and reason of nonsurgery in Hunt and Hess Grade IV or V were also examined. Outcome (good, poor, fair or dead) was assessed at 3 months after the first rupture. The patients with independent daily activity with or without minor deficit were categorized as favorable outcome, and the patients who died or depended daily living as unfavorable outcome.

\section{Results}

\section{Management outcome}

Management results of the 166 poor-grade patients were favorable in $71(42.8 \%)$ and unfavorable in 95 (78 dead, 17 poor) (57.2\%) (Table 1). There was big difference in management results between Hunt and Hess Grade IV and $\mathrm{V}$ patients, $57.0 \%$ of Grade IV patients achieved favorable outcome, but it was only $17.0 \%$ in Grade V patients. Number of unfavorable outcome in Grade V patients doubled that of Grade IV patients (Table 2).

\section{Results of surgery}

Results of surgery in the 90 poor-grade patients were favorable in $69(76.7 \%)$ and unfavorable in 21 (23.3\%). Surgery of the 73 Grade IV patients resulted in 60 (82.2\%) favorable outcome, but it was 9 (52.9\%) of the 17 Grade V patients. Surgical mortality of Grade V patients was about four times higher than Grade IV patients (Table 3). Surgery was not done in 76 patients because 41 were moribund on arrival, 15 deterioration due to rebleeding, 7 severe brain swelling, 5 serious medical illness, one severe DID, and one cerebral infarction following angiography, and 6 refused surgery. Seven patients survived in nonsurgery group (2 fair, 5 poor).

\section{Rebleeding}

Poor-grade patients (15.1\%) re-bled about three times more than good-grade (5.9\%) during hospital stay $(\mathrm{p}<$ 0.05). Early hospital rebleeding (within 72 hours after the admission) occurred in 18 patients (72.0\%) of the 25 poorgrade patients with rebleeding, and 13 patients (72.2\%) died. In contrast, early hospital rebleeding occurred in 9 (1.2\%) of the 25 good-grade patients with rebleeding $(\mathrm{p}<$ 
Table 3 Hunt and Hess grade and results of surgery

\begin{tabular}{|c|c|c|c|c|c|}
\hline \multirow{2}{*}{ Grade } & \multicolumn{4}{|c|}{ Outcome $(\%$ in row $)$} & \multirow{2}{*}{ Tota } \\
\hline & Good & Fair & Poor & Dead & \\
\hline I & $85(98.8)$ & $1(1.2)$ & & & 86 \\
\hline$\|$ & $145(90.6)$ & $5(3.1)$ & $8(5.0)$ & $2(1.3)$ & 160 \\
\hline ॥ा & $116(84.1)$ & $11(8.0)$ & $9(6.5)$ & $2(1.4)$ & 138 \\
\hline IV & $47(64.4)$ & $13(17.8)$ & $8(11.0)$ & $5(6.8)$ & 73 \\
\hline v & $4(23.5)$ & $5(29.5)$ & $4(23.5)$ & $4(23.5)$ & 17 \\
\hline Total & 397 & 35 & 29 & 13 & 474 \\
\hline
\end{tabular}

$0.05)$.

\section{Delayed ischemic deficits}

Incidence of DID in poor-grade patients was similar to good-grade patients. DID occurred in 41 (24.7\%) of the 166 poor-grade patients, and 96 (22.7\%) of the 422 good-grade patients. But DID was one of the major causes (7.4\%) of unfavorable outcome in poor-grade patients.

\section{Causes of unfavorable outcome}

Major causes of unfavorable outcome in the 95 poorgrade patients were direct insult in $61(64.2 \%)$ patients, 17 (17.9\%) rebleeding, and 7 (7.4\%) DID. Major causes of unfavorable outcome in Grade IV patients were direct insult (34.8\%) and rebleeding (34.8\%), while it was direct insults (91.8\%) in Grade V patients (Table 4). Surgical complication was only a minor causes of unfavorable outcome.

\section{Grade IV patients}

Management results of the 107 Hunt and Hess Grade IV patients were 61 (57.0\%) favorable and 46 (43.0\%) unfavorable (33 dead, 13 poor). Twenty-three Grade IV patients underwent early surgery within 72 hours of the last rupture, and resulted in 18 (78.3\%) favorable and 5 (21.7\%) unfavorable outcome. The other 84 Grade IV patients were managed conservatively with or without following delayed surgery, and their results were 43 (51.2\%) favorable and 41 (48.8\%) unfavorable: (1) Twelve patients were improved by supportive care. Eleven of them underwent delayed surgery and resulted in 10 favorable and one unfavorable outcome. One additional favorable outcome was a patient who did not have surgery. (2) Forty-two patients did not improve with conservative care. Thirty-seven of them underwent delayed surgery and resulted in 31 favorable and 6 unfavorable outcome. The other 5 patients refused surgery and their results were unfavorable. (3) Thirty patients deteriorated during supportive care ( 2 of them underwent delayed surgery) resulted in one favorable and 29 unfavorable outcome. Causes of deterioration during
Table 4 Causes of unfavorable outcome in poor-grade patients

\begin{tabular}{lcc}
\hline Cause & Grade IV & Grade V \\
\hline Direct insult & 16 & 45 \\
Rebleeding & 16 & 1 \\
Delayed ischemic deficits & 6 & 1 \\
Medical illness & 5 & 2 \\
Surgical complication & 1 & \\
Others & 2 & \\
\hline
\end{tabular}

supportive care were rebleeding in 16 patients, 7 brain swelling, 4 medical illness, 2 DID, and one cerebral infarction following angiography.

\section{Grade V patients}

Management results of the 59 Hunt and Hess Grade V patients were 10 (17.0\%) favorable and 49 (83.0\%) unfavorable ( 45 dead, 4 poor). Fourteen of the 59 Grade V patients underwent emergency surgery, and resulted in 7 favorable and 7 unfavorable outcome. Forty-five patients had supportive care first. Only 4 of the 45 patients with supportive care improved; 2 of 3 patients with delayed surgery and a patient without surgery achieved favorable outcome. Forty-one patients who did not improve with supportive care died.

\section{Discussion}

Although the duration of conservative care was not determined, poor-grade patients were excluded from early surgery in the hope of spontaneous improvement to a better grade. ${ }^{11)}$ But in the recent reports, the rate of favorable management outcome in poor-grade patients was improved from $20.2 \%$ to $42.6 \%$ with aggressive surgical management. ${ }^{3) 10) 14) 15)}$ Le Roux et al. reported results of a retrospective study in the 159 aggressively managed poorgrade patients (surgery in 96.9\%) with favorable outcome in $38.4 \%{ }^{9)}$ They could achieve favorable outcome in $53.9 \%$ of Grade IV, and $24.1 \%$ of Grade V patients. Our study in the 166 poor-grade patients (surgery in 54.2\%) resulted overall favorable outcome in $42.8 \%$; favorable outcome in 
Table 5 Authors and results of management in poor-grade patients with aneurysmal SAH

\begin{tabular}{|c|c|c|c|c|c|c|c|}
\hline \multirow[t]{3}{*}{ Author } & \multirow[t]{3}{*}{ Year } & \multirow{3}{*}{$\begin{array}{l}\text { No. of cases } \\
(\% \text { of Grade V) }\end{array}$} & \multirow{3}{*}{$\begin{array}{c}\text { No. of surgical } \\
\text { cases }(\%)\end{array}$} & \multicolumn{4}{|c|}{ Outcome in percent } \\
\hline & & & & \multicolumn{2}{|c|}{ Management } & \multicolumn{2}{|c|}{ Surgery } \\
\hline & & & & Favorable & Mortality & Favorable & Mortality \\
\hline Bailes et al. ${ }^{3 \mid}$ & 1990 & $54(59.3)$ & $35(64.9)$ & 42.6 & 50.0 & 65.7 & 22.9 \\
\hline Seifert et al. ${ }^{14 !}$ & 1990 & $74(35.1)$ & $36(48.6)$ & 20.2 & 67.4 & 41.7 & NA \\
\hline Nowak et al. ${ }^{12\}}$ & 1994 & $109(61.5)$ & $69(03.3)$ & 21.1 & 42.2 & 32.0 & 23.0 \\
\hline Steudel et al. ${ }^{16)}$ & 1994 & $116(73.3)$ & $57(49.1)$ & 35.3 & 56.9 & 71.9 & 22.8 \\
\hline Ungersböck et al. ${ }^{191}$ & 1994 & $48(39.6)$ & $36(75.0)$ & 21.3 & 42.5 & 27.8 & 22.2 \\
\hline Le Roux et al. ${ }^{9]}$ & 1996 & $159(52.2)$ & $154(96.9)$ & 38.4 & 43.4 & NA & NA \\
\hline Lee (present series) & 1997 & $166(35.5)$ & $90(54.2)$ & 42.8 & 47.0 & 76.7 & 10.0 \\
\hline
\end{tabular}

NA: Not applicable

$57.0 \%$ of Grade IV, and $17.0 \%$ in Grade V patients. Therefore, it appears that management results in poorgrade patients are similar both in non-selective and selective aggressive management (Table 5).

Poor-grade patients have been often excluded from aggressive management on the basis of concepts that surgery and anesthesia would aggravate the brain damage. ${ }^{16) 18)}$ However, recent reports support that the risk of surgical complication is similar both in good and poorgrade patients undergoing surgical repair of ruptured anterior circulation aneurysms. ${ }^{10) 16)}$

Steudel et al. reported that surgery was beneficial in the cases showing clinical improvement. ${ }^{16)}$ Patients with clinical improvement following ventriculostomy or conservative management showed favorable outcome in $89.5 \%{ }^{17}$ ) The International Cooperative Study on the Timing of Aneurysm Surgery demonstrated that the risk of early surgery was equivalent to the risk of rebleeding and vasospasm in patients waiting for delayed surgery. ${ }^{8)}$ Seifert et al. reported that early surgery in Grade IV patients led to better overall mortality and morbidity than delayed surgery, and chance of survival in poor-grade patients without surgery is almost none existent. ${ }^{14)}$ In our study, $28.0 \%$ of Grade IV patients deteriorated during conservative management, and rebleeding was one of the main causes of deterioration. This results suggests that aggressive management is necessary for prevention of rebleeding.

Rebleeding within two weeks was more common in poor-grade (21.6\%) than good grade (11.6\%) patients. ${ }^{7) 13)}$ Hillman et al. reported $79.2 \%$ mortality in the patients who had rebleeding within 24 hours. ${ }^{5)}$ This study also shows that rebleeding during hospital stay was more frequent in poor (15.1\%) than good-grade (5.9\%). Early rebleeding within 72 hours after the first rupture was more common and caused high mortality in the poor-grade patients. There was a clear prognostic difference regarding unfavorable outcome between Grade IV and V patients. ${ }^{14) 19)}$ As early rebleeding (28.0\%) is one of the major causes of unfavorable outcome in Grade IV patients, urgent surgical intervention is necessary for these patients. Steudel et al. recommended early active surgery if Grade $\mathrm{V}$ patients with Glasgow Coma Scale above 4 improve after ventriculostomy. ${ }^{16)}$ Early active surgical treatment for all poor-grade patients decreased mortality without affecting favorable outcome. ${ }^{9)}$ Our experience favors early active surgery for Grade $\mathrm{V}$ patients with increased intracranial pressure caused by intracerebral hematoma or acute hydrocephalus. Selected poor-grade patients could be salvaged by ventriculostomy and subsequent surgical clipping or coil embolization. But increased risk of rebleeding among patients undergoing ventriculostomy was also reported. $^{2) 16)}$ Therefore it is necessary to protect from rebleeding as soon as patients improve with ventriculostomy. ${ }^{29)}$

\section{References}

1) Adams HP Jr., Kassell NF, Torner JC, et al: Early management of aneurysms subarachnoid hemorrhage. A report of the cooperative aneurysm study. J Neurosurg 54: 141-145, 1981

2) Arnold H, Schwachenwald R, Nowak G, et al: Aneurysm surgery in poor grade patients. Results, and value of external ventricular drainage. Neurol Res 16: 45-48, 1994

3) Bailes JE, Spetzler RF, Hadley MN, et al: Management morbidity and mortality of poor-grade aneurysm patients. J Neurosurg 72: 559-566, 1990

4) Disney L, Weir B, Grace M: Factors influencing the outcome of aneurysm rupture in poor grade patients: a prospective series. Neurosurgery 23: 1-9, 1988

5) Hillman J, von Essen C, Leszniewski W, et al: Significance of "ultra-early" rebleeding in subarachnoid hemorrhage. J Neurosurg 68: 901-907, 1988

6) Hunt WE, Hess RM: Surgical risk as related to time of intervention in the repair of intracranial aneurysms. J Neurosurg 
28: 14-20, 1968

7) Kassell NF, Torner JC: Aneurysmal rebleeding: a preliminary report from the cooperative aneurysm study. Neurosurgery 13: 479-481, 1983

8) Kassell NF, Torner JC, Jane JA, et al: The international cooperative study on the timing of aneurysm surgery. Part 2: surgical results. J Neurosurg 73: 37-47, 1990

9) Le Roux PD, Elliott JP, Newell DW, et al: Predicting outcome in poor-grade patients with subarachnoid hemorrhage: a retrospective review of 159 aggressively managed cases. J Neurosurg 85: 39-49, 1996

10) Le Roux PD, Elliott JP, Newell DW, et al: The incidence of surgical complications is similar in good and poor grade patients undergoing repair of ruptured anterior circulation aneurysms: a retrospective review of 355 patients. Neurosurgery 38: 887-895, 1996

11) Ljunggren B, Säveland H, Brandt L: Causes of unfavorable outcome after early aneurysm operation. Neurosurgery 13: 629-633, 1983

12) Nowak G, Schwachenwald R, Arnold H: Early management in poor grade aneurysm patients. Acta Neurochir 126: 33-37,
1994

13) Rosenørn J, Eskesen V, Schmidt K, et al: The risk of rebleeding from ruptured intracranial aneurysms. J Neurosurg 67: 329-332, 1987

14) Seifert V, Trost HA, Stolke D: Management morbidity and mortality in grade IV and V patients with aneurysmal subarachnoid haemorrhage. Acta Neurochir 103: 5-10, 1990

15) Spetzger U, Gilsbach JM: Results of early aneurysm surgery in poor grade patients. Neurol Res 16: 27-30, 1994

16) Steudel W, Reif J, Voges M: Modulated surgery in the management of ruptured intracranial aneurysm in poor grade patients. Neurol Res 16: 49-53, 1994

17) Taylor B, Harries P, Bullock R: Factors affecting outcome after surgery for intracranial aneurysm in Glasgow. $\mathrm{Br} \mathrm{J}$ Neurosurg 5: 591-600, 1991

18) Testa C, Andreoli A, Arista A, et al: Overall results in 304 consecutive patients with acute spontaneous subarachnoid hemorrhage. Surg Neurol 24: 377-385, 1985

19) Ungersböck K, Böcher-Schwarz H, Ulrich P, et al: Aneurysm surgery of patients in poor grade condition. Indications and experience. Neurol Res 16: 31-34, 1994 